\title{
Absorption of Fluorinated Greenhouse Gases using
}

\section{Fluorinated Ionic Liquids}

Julio E. Sosa, Rui P. P. L. Ribeiro, Paulo J. Castro, José P. B. Mota, João M. M. Araújo,* Ana B. Pereiro*

LAQV, REQUIMTE, Department of Chemistry, Faculdade de Ciências e Tecnologia, Universidade Nova de Lisboa, 2829-516 Caparica. Portugal.

ABSTRACT: The increasing awareness of the environmental impact of fluorinated gases (Fgases) used in refrigeration is instigating the development of technologies to recover and recycle them. With this goal in mind, single-component absorption equilibrium isotherms at $303.15 \mathrm{~K}$ of F-gases in different ionic liquids (ILs) were determined using a gravimetric method. The selected F-gases are the most used in domestic refrigeration (R-32: difluoromethane, R-125: pentafluoroethane, and R-134a: 1,1,1,2-tetrafluoroethane). The results show that ILs containing a fluorinated alkyl side chain with four carbon atoms, i.e., fluorinated ionic liquids (FILs), have higher gas absorption capacity than conventional fluoro-containing ILs. All studied ILs showed ideal selectivity towards R-134a. Conventional fluoro-containing ILs showed better selectivities for the separation of the binary mixtures R-134a/R-125 and R-32/R-125 and FILs showed better selectivities for the R-134a/R-32 mixture. These results provide fundamental knowledge of the behavior of these new alternative solvents and key information for their application in the separation of F-gases mixtures of commercial refrigerants. 


\section{INTRODUCTION}

Global temperature is raising every year, mostly due to the increasing concentrations of atmospheric greenhouse gases (GHG). ${ }^{1}$ Although carbon dioxide $\left(\mathrm{CO}_{2}\right)$ accounts for at least twothirds of the global GHG emissions, ${ }^{2}$ fluorinated gases (F-gases), such as the families of hydrofluorocarbons (HFCs) and perfluorocarbons (PFCs), as well as sulfur hexafluoride ( $\left.\mathrm{SF}_{6}\right)$, are also major contributors to global warming. ${ }^{3}$ The emissions of these gases have increased $60 \%$ since $1990^{4}$ and HFCs emissions are projected to grow by nearly $140 \%$ between 2005 and $2020 .{ }^{5}$ In order to accomplish the EU commitments related to Kyoto's Protocol, the use of F-gases has been controlled since 2006. The different legislations aim to combat the effect of these compounds on global warming. A new EU regulation was applied on 1 January 2015 (No. 517/2014) with the aim to cut F-gases emissions by two-thirds compared to 2014 levels, until $2030 .{ }^{5}$ This represents a decisive contribution to the EU's objective of cutting its overall GHG emissions by $80-95 \%$, compared to 1990 levels, by $2050 .^{5}$

Moreover, an international agreement was signed in Kigali in 2016. This agreement established the first international regulation to decrease the amount of F-gases emissions. ${ }^{6}$ This deal includes: (i) provisions to prohibit and/or restrict countries that have ratified the protocol or its amendments from trading controlled substances with states that have not yet ratified the protocol; (ii) specific targets and timetables to replace HFCs with more environmental friendly alternative refrigerants; (iii) and an agreement by rich countries to help financing the transition of poor countries to alternative safer products. $^{7}$

F-gases have a powerful global warming potential (GWP), some of them reaching a value 23,000 times higher than that of $\mathrm{CO}_{2},{ }^{8}$ and have an atmospheric lifetime up to 50,000 years. ${ }^{1}$ These compounds are a family of man-made gases widely used for several industrial applications (e.g. air-conditioning systems, industrial refrigeration, fire extinguishants, solvents). ${ }^{8} \mathrm{~F}$-gases began to be massively used in 1989 to replace chlorofluorocarbons (CFCs) and hydrochlorofluorocarbons 
(HCFCs), which were phased out under the Montreal Protocol because they damage the ozone layer. F-gases are energy efficient, do not damage the ozone layer, can be considered non-toxic, and exhibit low levels of flammability. ${ }^{1}$

The actual lack of developed technologies to recycle F-gases dramatically affects the refrigeration sector because most F-gases are incinerated, thereby increasing the atmospheric emissions of these gases. In few cases, F-gases are partially recovered using expensive processes involving adsorption on activated carbon, cryo-condensation, or membrane separation. ${ }^{9}$ Therefore, there is great interest in the development of a sustainable process based on circular economy, which uses environmentally benign solvents to capture, recover, and recycle F-gases, avoiding their emissions to the atmosphere.

As an alternative to conventional traditional solvents, ionic liquids (ILs) are currently being investigated and used industrially for various separation applications. ${ }^{10,11} \mathrm{ILs}$ present exceptional properties, such as non-volatility, null flammability, low melting point, high ionic conductivity, thermal and electrochemical stability, and a remarkable recyclability. ${ }^{12}$ One of the most attractive characteristics of ILs is that their properties can be fine-tuned through the careful selection of cations and anions in order to achieve the desired properties for each specific application.

An emerging research topic of interest is the increment of ILs tuneability. ${ }^{12}$ In this sense, fluorinated ionic liquids (FILs) containing fluorinated alkyl chains with at least four carbon atoms form three nanosegregated domains (polar, nonpolar, and fluorinated). ${ }^{13}$ These three domains exhibit completely different behaviors and a unique ability to solubilize and interact with three totally different moieties at the same time. This nanosegregation increases the number of different conformations of these solvents, thereby facilitating interactions with different solutes and increasing their solubilization and tuneability. ${ }^{14,15}$ The use of FILs enables us to combine the unique properties of two unconventional families: (i) highly fluorinated biomaterials, that have outstanding chemical and biological inertness and that offer unique components and tools for the 
engineering of stable, self-assembled supramolecular systems; and (ii) ILs, with their tunable solvation, vanishingly low vapor pressure, and greener potential. ${ }^{16}$ In addition, FILs containing short perfluorinated alkyl chains are non-toxic in four different human cell lines ${ }^{17,18}$ and are fully water-soluble. ${ }^{19}$ These numerous intrinsic properties make FILs very attractive for separation processes. The vast range of possible variations in the size of the fluorinated domain and the different types of interactions (van der Waals, coulombic, and hydrogen bonding), allows the design of an ideal three-in-one solvent for separation of fluorinated GHGs. This has propelled us to study the effect of using ILs with fluorine atoms in the anion in order to increase the absorption capacities for F-gases.

This paper aims to contribute to the development and implementation of environmentally friendly, IL-based separation processes for recovering and recycling F-gases. With this goal in mind, we have studied: (i) one IL lacking fluorine atoms $\left(\left[\mathrm{C}_{2} \mathrm{C}_{1} \mathrm{Im}\right]\left[\mathrm{C}_{1} \mathrm{CO}_{2}\right]\right)$ as reference IL for gas solubility, due to a literature review that clearly shows that this IL has strong chemical absorption capacity for several gases, including $\mathrm{CO}_{2}{ }^{20}$; (ii) two conventional fluoro-containing ILs $\left(\left[\mathrm{C}_{2} \mathrm{C}_{1} \mathrm{Im}\right]\left[\mathrm{CF}_{3} \mathrm{SO}_{3}\right]\right.$ and $\left.\left[\mathrm{C}_{2} \mathrm{C}_{1} \mathrm{Im}\right]\left[\mathrm{N}\left(\mathrm{CF}_{3} \mathrm{SO}_{2}\right)_{2}\right]\right)$ since $\mathrm{ILs}$ containing $\left[\mathrm{CF}_{3} \mathrm{SO}_{3}\right]^{-}$and $\left[\mathrm{N}\left(\mathrm{CF}_{3} \mathrm{SO}_{2}\right)_{2}\right]^{-}$have been widely studied for the sorption of F-gases ${ }^{21-23,26}$; and (iii) three different FILs, $\left[\mathrm{C}_{2} \mathrm{C}_{1} \mathrm{Im}\right]\left[\mathrm{C}_{4} \mathrm{~F}_{9} \mathrm{CO}_{2}\right],\left[\mathrm{C}_{2} \mathrm{C}_{1} \mathrm{Im}\right]\left[\mathrm{C}_{4} \mathrm{~F}_{9} \mathrm{SO}_{3}\right]$, and $\left[\mathrm{C}_{2} \mathrm{C}_{1}\right.$ py $]\left[\mathrm{C}_{4} \mathrm{~F}_{9} \mathrm{SO}_{3}\right]$, in order to evaluate the sorption capacity of ILs with a fluorinated nanosegregated domain. We evaluated the capacities of these ILs for capturing, separating, and storing the most commonly employed F-gases in domestic refrigeration: R32 (difluoromethane), R125 (pentafluoroethane), and R134a (1,1,1,2tetrafluoroethane). ${ }^{27}$ For each F-gas, we have measured single-component absorption/desorption isotherms at $303.15 \mathrm{~K}$ and pressures ranging from 0.02 to $0.5 \mathrm{MPa}$ in the selected ILs. Experimental data were correlated with the non-random two-liquid (NRTL) model. ${ }^{28,29}$ Furthermore, the separation capacity of the studied ILs for binary F-gases mixtures was investigated using selectivity data. The results of this work provide fundamental understanding of the behavior of these new 
alternative solvents and provide key data to design and scale-up FIL-based processes for the recovery of F-gases.

\section{MATERIALS AND METHODS}

2.1. Materials. 1-Ethyl-3-methylimidazolium acetate $\left(\left[\mathrm{C}_{2} \mathrm{C}_{1} \mathrm{Im}\right]\left[\mathrm{C}_{1} \mathrm{CO}_{2}\right],>90 \%\right.$ mass fraction purity), 1-ethyl-3-methylimidazolium perfluoromethanesulfonate $\left(\left[\mathrm{C}_{2} \mathrm{C}_{1} \mathrm{Im}\right]\left[\mathrm{CF}_{3} \mathrm{SO}_{3}\right],>99 \%\right.$ mass fraction purity), 1-ethyl-3-methylimidazolium bis(trifluoromethylsulfonyl)imide $\left(\left[\mathrm{C}_{2} \mathrm{C}_{1} \mathrm{Im}\right]\left[\mathrm{N}\left(\mathrm{CF}_{3} \mathrm{SO}_{2}\right)_{2}\right], \quad 99.5 \%\right.$ mass fraction purity), 1-ethyl-3-methylimidazolium perfluorobutanesulfonate $\left(\left[\mathrm{C}_{2} \mathrm{C}_{1} \mathrm{Im}\right]\left[\mathrm{C}_{4} \mathrm{~F}_{9} \mathrm{SO}_{3}\right],>97 \%\right.$ mass fraction purity), and 1-ethyl-3methylpyridinium perfluorobutanesulfonate $\left(\left[\mathrm{C}_{2} \mathrm{C}_{1}\right.\right.$ py $]\left[\mathrm{C}_{4} \mathrm{~F}_{9} \mathrm{SO}_{3}\right],>97 \%$ mass fraction purity $)$ were supplied by IoLiTec GmbH. 1-Ethyl-3-methylimidazolium perfluoropentanoate $\left(\left[\mathrm{C}_{2} \mathrm{C}_{1} \mathrm{Im}\right]\left[\mathrm{C}_{4} \mathrm{~F}_{9} \mathrm{CO}_{2}\right],>99 \%\right.$ mass fraction purity) was previously synthesized, through an ionexchange resin method, and characterized in our laboratory. ${ }^{30,31}$ Detailed structure and nomenclature of FILs is shown in Table 1. Purity of all ionic liquids was checked by ${ }^{1} \mathrm{H}$ and ${ }^{19} \mathrm{~F}$ NMR as well as by Elemental Analysis. To ensure the absence of water and volatiles all FILs were dried under vacuum (4 Pa) and vigorously stirred at $323.15 \mathrm{~K}$ for at least 48 hours, immediately prior to their use. After drying, water content was verified to be less than $100 \mathrm{ppm}$ by volumetric Karl-Fischer titration technique (Metrohm Ion analysis, $831 \mathrm{KF}$ Coulometer). Each sample was taken from the respective Schlenk flask with a syringe under nitrogen flow to avoid humidity and immediately placed in the measuring devices.

F-gases R32 (difluoromethane, $\geq 99.8 \%$ mass fraction purity), R125 (pentafluoroethane, $\geq 99.8$ $\%$ mass fraction purity), and $\mathrm{R} 134 \mathrm{a}(1,1,1,2-$ tetrafluoroethane, $\geq 99.8 \%$ mass fraction purity) (Table 2) were acquired from Polo Zero. 
Table 1. Chemical Structures and Acronyms of the Ionic Liquids Used in this Work

\section{Ionic Liquid Designation}

1-Ethyl-3-methylimidazolium acetate

$\left[\mathrm{C}_{2} \mathrm{C}_{1} \operatorname{Im}\right]\left[\mathrm{C}_{1} \mathrm{CO}_{2}\right]$

1-Ethyl-3-methylimidazolium triflate

$\left[\mathrm{C}_{2} \mathrm{C}_{1} \mathrm{Im}\right]\left[\mathrm{CF}_{3} \mathrm{SO}_{3}\right]$

1-Ethyl-3-methylimidazolium

bis(trifluoromethylsulfonyl)imide

$\left[\mathrm{C}_{2} \mathrm{C}_{1} \mathrm{Im}\right]\left[\mathrm{N}\left(\mathrm{CF}_{3} \mathrm{SO}_{2}\right)_{2}\right]$

1-Ethyl-3-methylimidazolium perfluoropentanoate

$\left[\mathrm{C}_{2} \mathrm{C}_{1} \mathrm{Im}\right]\left[\mathrm{C}_{4} \mathrm{~F}_{9} \mathrm{CO}_{2}\right]$
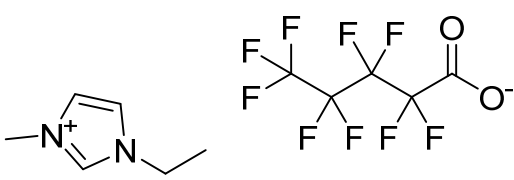

1-Ethyl-3-methylimidazolium perfluorobutanesulfonate $\left[\mathrm{C}_{2} \mathrm{C}_{1} \mathrm{Im}\right]\left[\mathrm{C}_{4} \mathrm{~F}_{9} \mathrm{SO}_{3}\right]$
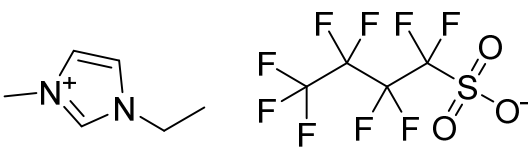

1-Ethyl-3-methylpyridinium perfluorobutanesulfonate $\left[\mathrm{C}_{2} \mathrm{C}_{1}\right.$ py $]\left[\mathrm{C}_{4} \mathrm{~F}_{9} \mathrm{SO}_{3}\right]$

\section{Chemical Structure}<smiles>CCn1cc[n+](C)c1</smiles>

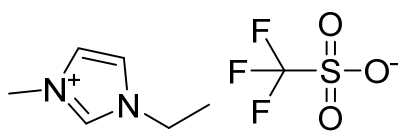<smiles>O=S(=O)([N-]S(=O)(=O)C(F)(F)F)C(F)(F)F</smiles>

O 
2.2. Experimental Procedure. Single-component absorption equilibrium isotherms for the aforementioned R-32, R-125, and R-134a gases in FILs were determined at $303.15 \mathrm{~K}$ and pressures ranging from 0.02 to $0.5 \mathrm{MPa}$. Data were acquired using a standard gravimetric method, which consists in the stepwise supply of the pure fluorinated gas to the measurement cell containing the pure IL sample (approximately $0.3 \mathrm{~g}$ ). To ensure the absence of water and volatile substances' contents all FILs were dried in-situ under vacuum at $323.15 \mathrm{~K}$ for at least 12 hours, immediately prior to their use. The whole system was kept isothermal at $303.15 \mathrm{~K}$ throughout the stepwise equilibrium steps generated along the absorption/desorption cycles. Mass and pressure variations were monitored until equilibrium was achieved in the cell.

Figure 1 shows a schematic diagram of the equipment used for these experiments. ${ }^{32-34}$ It consists in a high-accuracy ISOSORP 2000 high-pressure magnetic-suspension balance (Rubotherm $\mathrm{GmbH}$, Germany) with a $10^{-5} \mathrm{~g}$ resolution, uncertainty $\leq 0.002 \%$ and reproducibility $\leq 3 \cdot 10^{-5} \mathrm{~g}$ for a maximum load of $25 \mathrm{~g}$. Isothermal conditions are ensured by using a thermostatic bath F32 HL $( \pm 0.1 \mathrm{~K})$ from Julabo GmbH (Germany). Pressure is measured with a couple of pressure transducers that guarantee good measurement accuracy over all pressure ranges of operation: firstly, one Baratron model 627D (MKS Instruments GmbH, Germany) for 0-0.1 MPa, accuracy of $0.12 \%$ of the reading; and secondly an Omegadyne Inc. (Sunbury, OH, USA) model PX01C1150A5T for 0-1 MPa (accuracy of $0.05 \%$ of Full Scale, FS). Further details about the experimental apparatus can be found elsewhere. ${ }^{32-34}$ 


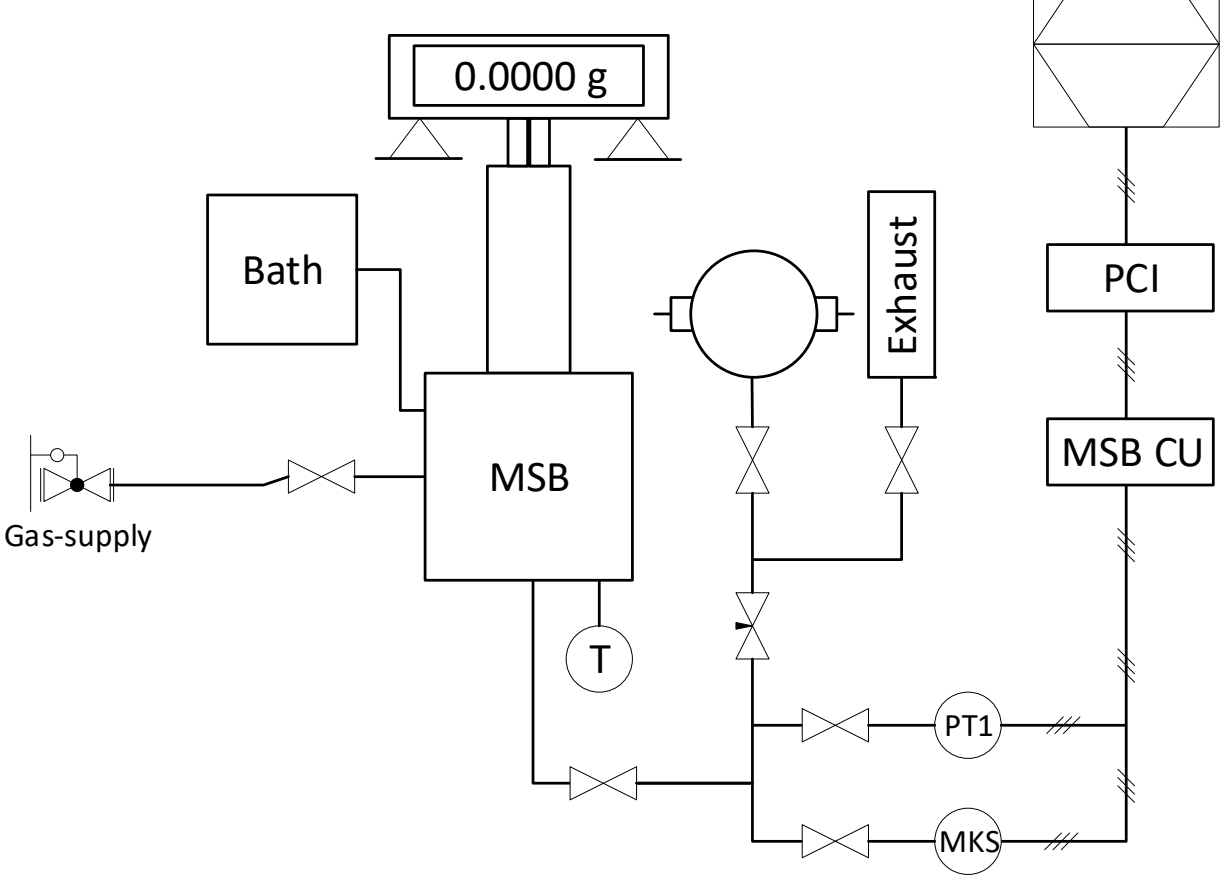

Figure 1. Schematic diagram of the experimental set up (MSB: magnetic suspension microbalance where PCI is the PC interface for data acquisition, T is the Pt100 temperature sensor, PT represents the Omegadyne pressure transducer and MKS is the MKS Baratron pressure transducer).

The apparent mass of sorbed gas, $w$, i.e., the recorded weight at a given applied gas pressure $p$ minus the initial recorded weight at 0 bar, measured by the balance under isothermal conditions, is related to the absolute gas solubility, $n$ (mass of dissolved gas per unit mass of sorbent), as follows:

$$
w=m_{s} n-\left[V_{\mathrm{c}}+m_{s} \tilde{v}_{s}(T, p, x)\right] \rho_{\mathrm{g}}
$$

where $m_{s}$ is the mass or sorbent sample (i.e., pure IL), $V_{\mathrm{c}}$ is the skeletal volume of the holding basket $\left(V_{\mathrm{c}}=m_{c} \rho_{c}\right.$, where $m_{c}$ and $\rho_{c}$ are the mass and density of the material of which the basket is made of $), \rho_{\mathrm{g}}(T, p)$ is the density of the gas at pressure $p$ and temperature $T$, and $\tilde{v}_{S}(T, p, x)$ is the specific volume of the IL/gas system on a solute-free basis (mixture volume per unit mass of IL) at the $p, T$ conditions of the experiment and mass fraction of dissolved gas $y=n /(1+n)$.

However, the quantity that is directly extracted from a gravimetric or volumetric experiment is the net gas solubility, $n^{\text {net }}$, defined as: 


$$
w=m_{s} n^{\text {net }}-V_{\mathrm{c}} \rho_{\mathrm{g}}
$$

whose calculation does not require any information about the IL/gas system besides the initial mass of the sample; $n^{\text {net }}$ is a particularly important volume-basis metric for gas storage but much less so for gas separation.

A more useful and well-defined thermodynamic quantity, whose calculation does not depend upon any knowledge or assumption about how the dissolved gas changes the volume of the IL/gas system, is the excess gas solubility, $n^{\text {ex }}$, defined as:

$$
n^{\mathrm{ex}}=n^{\mathrm{net}}+\tilde{v}_{S}(T, p, 0) \rho_{\mathrm{g}}
$$

where $\tilde{v}_{S}(T, p, 0)$ is the specific volume of the pure $\operatorname{IL}(y=0)$ at system temperature and imposed gas pressure $p$.

Invariably, $\tilde{v}_{s}(T, p, y)$ must be known or estimated in order to calculate the absolute gas solubility whether directly from eq. (1), or from $n^{\text {ex }}$ via:

$$
n=n^{\mathrm{ex}}+\left[\tilde{v}_{s}(T, p, y)-\tilde{v}_{s}(T, p, 0)\right]=n^{\mathrm{ex}}+\Delta \tilde{v}_{s}(T, p, y) \rho_{\mathrm{g}}
$$

where $\Delta \tilde{v}_{S}(T, p, y)$ is the specific volume change due to the dissolved gas. If the IL/gas mixture is an ideal fluid mixture, which is assumed to hold in the present work,

$$
\Delta \tilde{v}_{s}(T, p, y)=v_{\mathrm{g}}^{1}(T) n=v_{\mathrm{g}}^{1}(T) \frac{1}{1-y}
$$

where $v_{\mathrm{g}}^{1}(T)$ is the specific volume of the liquified gas under saturation conditions at the system temperature $T$.

Gas solubility is commonly reported in terms of molar fraction of dissolved gas, $x$, and the conversion from $n$ to $x$ is straightforward:

$$
x=\frac{n / M_{\mathrm{g}}}{1 / M_{\mathrm{IL}}+n / M_{\mathrm{g}}}
$$

where $M_{\mathrm{g}}$ and $M_{\mathrm{IL}}$ are the molecular weights of the gas and IL, respectively. 
This experimental procedure was validated using the pure IL $\left[\mathrm{C}_{2} \mathrm{C}_{1} \mathrm{Im}\right]\left[\mathrm{N}\left(\mathrm{CF}_{3} \mathrm{SO}_{2}\right)_{2}\right]$ for $\mathrm{CO}_{2}$ absorption. The obtained results were compared with published data ${ }^{35}$ and are plotted in Figure S1 of Supporting Information.

\section{RESULTS AND DISCUSSION}

\subsection{Gas Solubility in ILs.}

The ionic liquids studied in this work have improved capacity of solubilization of F-gases in relation to most conventional organic absorbents. ${ }^{36-39}$ In Figure 2, the moles of adsorbed F-gas per unit of absorbent mass (ILs or conventional organic solvents) determined is illustrated at $303.15 \mathrm{~K}$ and equilibrium pressures (0.1 MPa for R-32 and 0.3 MPa for R-134a). In the case of R-32, all studied ILs show better solubilization performance relatively to organic solvents and for R-134a only two solvents, monoethylene glycol dimethyl ether and tetraethylene glycol dimethyl ether ${ }^{38,39}$, showed better performance than ILs. No data were found in the literature regarding to the R-125 absorption in organic solvents. 


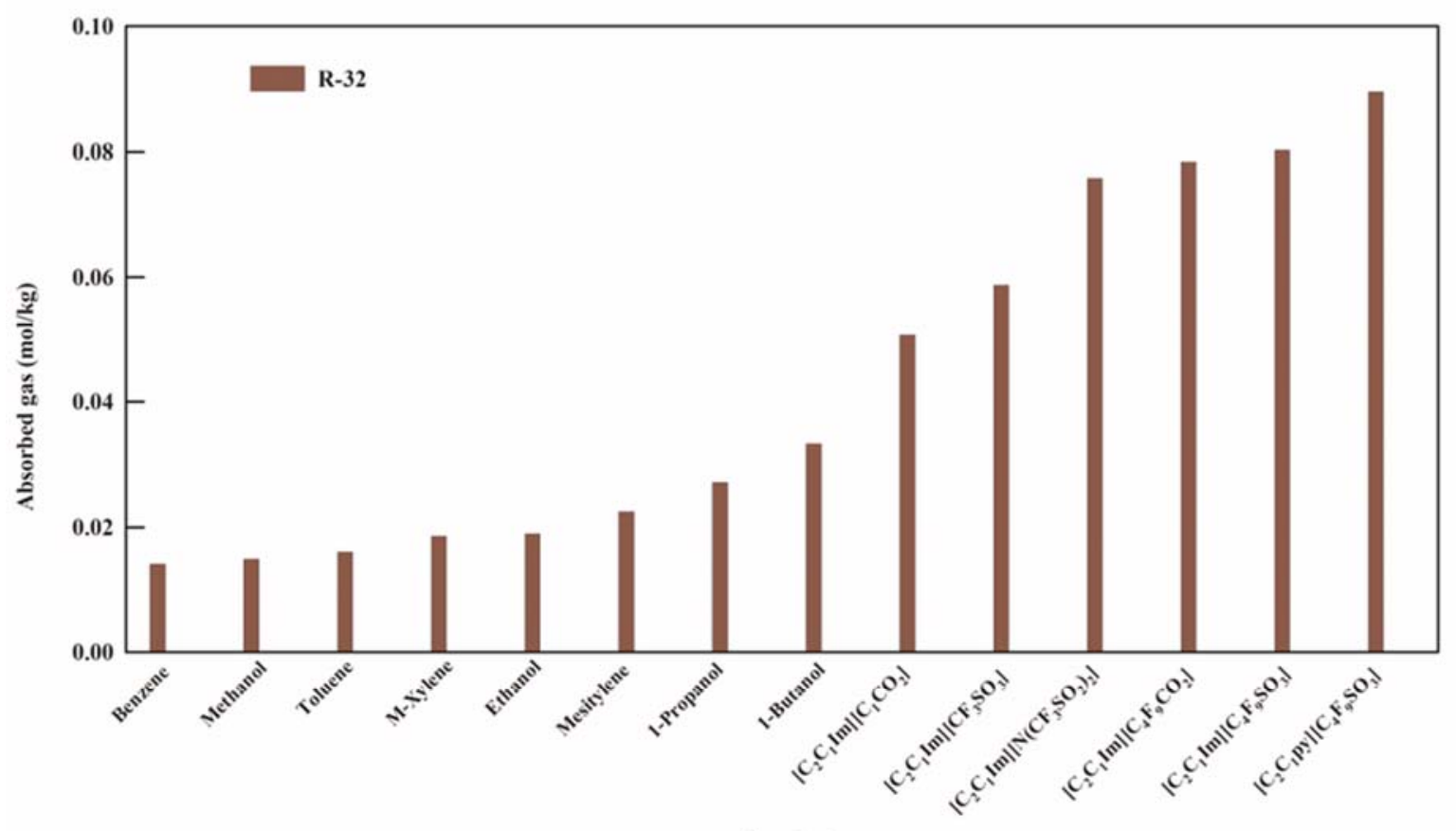

Absorbent

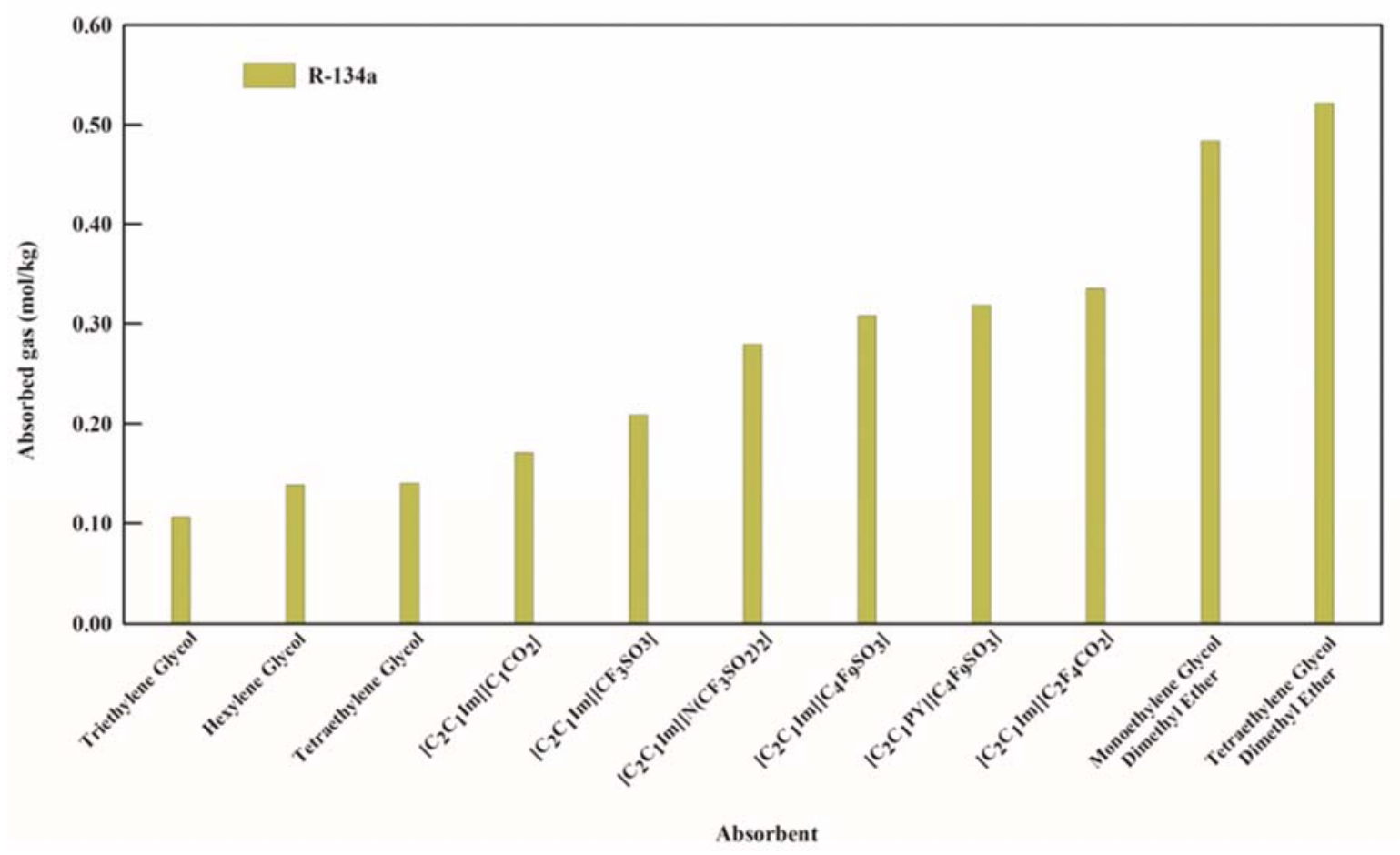

Figure 2. Comparison of the absorption of R-32 and R-134a in the ILs studied in this work and in conventional organic solvents. ${ }^{36-39}$ Absorption was determined at $303.15 \mathrm{~K}$ and equilibrium pressures of 0.1 MPa (for R-32) or $0.3 \mathrm{MPa}$ (for R-134a). 
The experimental solubility data, expressed as mole fraction of dissolved gas $\left(x_{i}\right)$, of each F-gas, $i$,in the six ILs are presented in Figure 3 as a function of the applied equilibrium gas pressure $(0.02$ to $0.5 \mathrm{MPa}$ ) at $303.15 \mathrm{~K}$ (see also Table $\mathrm{S} 1$ of Supporting Information). The absorption equilibrium isotherms were studied up to $0.5 \mathrm{MPa}$ in order to not exceed the lowest saturation pressure of the F-gases studied in this work (0.77 MPa for R-134a, 1.57 MPa for R-125 and 1.92 MPa for R-32). The absorption and desorption isotherms shown in Figure 3 are superimposable, indicating the inexistence of hysteresis between the absorption and desorption branches.
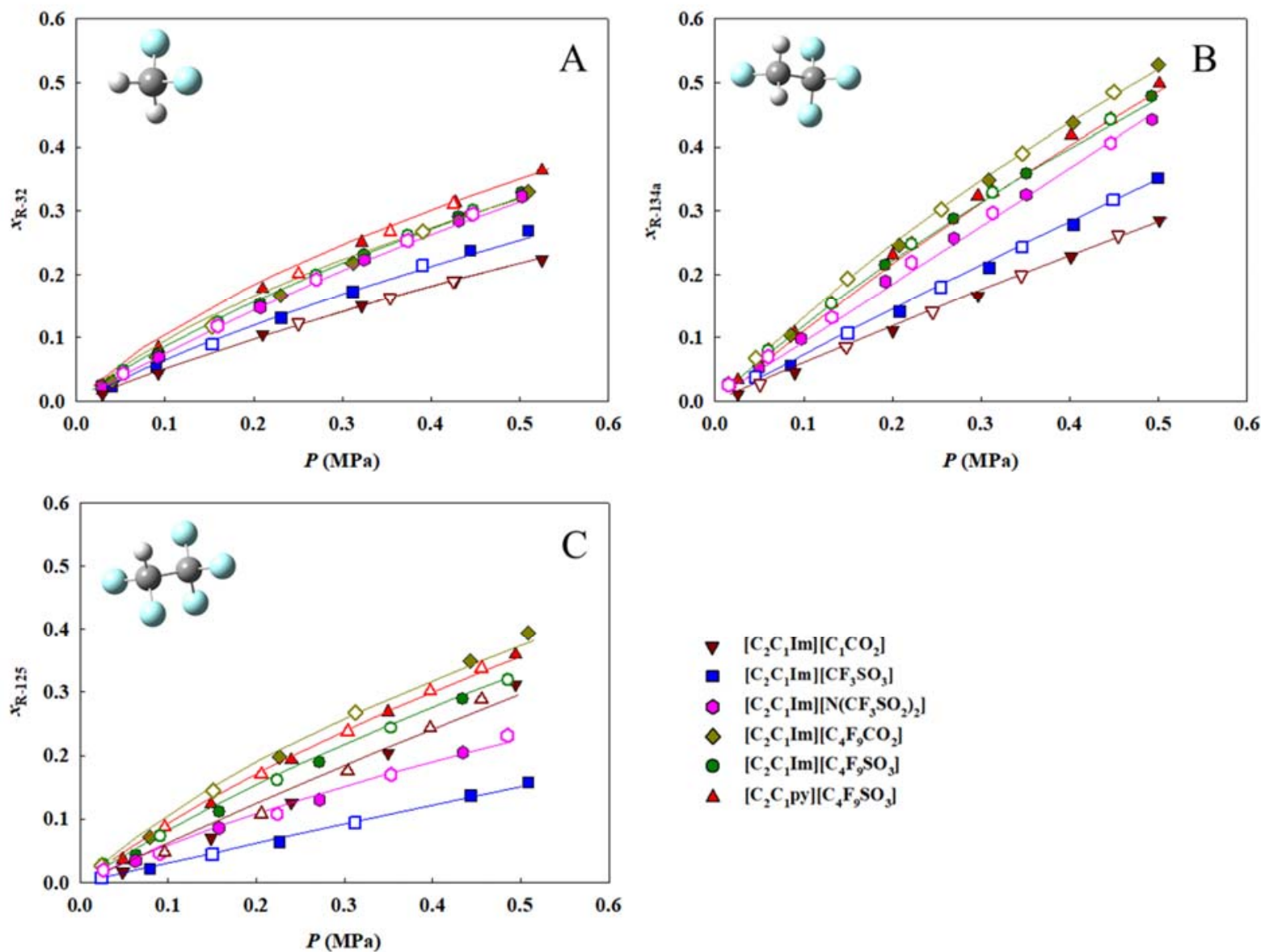

- $\left[\mathrm{C}_{2} \mathrm{C}_{1} \mathrm{Im}\right]\left[\mathrm{C}_{1} \mathrm{CO}_{2}\right]$

- $\left[\mathrm{C}_{2} \mathrm{C}_{1} \mathrm{Im}\right]\left[\mathrm{CF}_{3} \mathrm{SO}_{3}\right]$

- $\left[\mathrm{C}_{2} \mathrm{C}_{1} \mathrm{Im}\right]\left[\mathbf{N}\left(\mathrm{CF}_{3} \mathrm{SO}_{2}\right)_{2}\right]$

$\diamond\left[\mathrm{C}_{2} \mathrm{C}_{1} \mathrm{Im}\right]\left[\mathrm{C}_{4} \mathrm{~F}_{9} \mathrm{CO}_{2}\right]$

- $\left[\mathrm{C}_{2} \mathrm{C}_{1} \mathrm{Im}\right]\left[\mathrm{C}_{4} \mathrm{~F}_{9} \mathrm{SO}_{3}\right]$

$\Delta \quad\left[\mathrm{C}_{2} \mathrm{C}_{1} \mathrm{py}\right]\left[\mathrm{C}_{4} \mathrm{~F}_{9} \mathrm{SO}_{3}\right]$

Figure 3. Absorption (full symbols) and desorption (empty symbols) isotherms of R-32 (panel A), R-134a (panel B), and R-125 (panel C) refrigerants in different ILs, determined at $303.15 \mathrm{~K}$ and equilibrium pressures ranging from 0.02 to $0.5 \mathrm{MPa}$. Solid lines are the NRTL model calculations. 
One of the most remarkable characteristics of ILs is their high tuneability. Therefore, absorption capacity and selectivity for a specific gas can be improved by combining different cations and anions. We studied six different ILs based on two cations $\left(\left[\mathrm{C}_{2} \mathrm{C}_{1} \mathrm{Im}\right]^{+}\right.$and $\left.\left[\mathrm{C}_{2} \mathrm{C}_{1} \text { py }\right]^{+}\right)$and on five anions $\left(\left[\mathrm{C}_{1} \mathrm{CO}_{2}\right]^{-},\left[\mathrm{CF}_{3} \mathrm{SO}_{3}\right]^{-},\left[\mathrm{N}\left(\mathrm{CF}_{3} \mathrm{SO}_{2}\right)_{2}\right]^{-},\left[\mathrm{C}_{4} \mathrm{~F}_{9} \mathrm{SO}_{3}\right]^{-}\right.$and $\left.\left[\mathrm{C}_{4} \mathrm{~F}_{9} \mathrm{CO}_{2}\right]^{-}\right)$. In this way, it is possible to study how gas solubility is affected by: (i) cation nature (presence of either an imidazolium- or pyridinium-based cation); (ii) presence of fluorine atoms or alkyl fluorinated chains in the anion; and (iii) anion nature (presence of either a sulfonate or a carboxylate group in the alkyl fluorinated chain of the anion). Gas absorption in ILs can be intrinsically related to the physicochemical and transport properties of the ILs studied in this work, which are summarized in Table 3. ${ }^{12,30,40,41}$

Table 3. Values of Dynamic Viscosity $(\eta)$, Density $(\rho)$, Refractive Index $\left(n_{\mathrm{D}}\right)$, Molar Volume $\left(V_{\mathrm{m}}\right)$, And Molar Refraction $\left(R_{\mathrm{m}}\right)$ of Ionic liquids at 303.15 K.

\begin{tabular}{llllll} 
Ionic Liquid & $\eta(\mathrm{mPa} \cdot \mathrm{s})$ & $\rho\left(\mathrm{g} \cdot \mathrm{cm}^{-3}\right)$ & $n_{\mathrm{D}}$ & $V_{\mathrm{m}}\left(\mathrm{cm}^{3} \cdot \mathrm{mol}^{-1}\right)$ & $R_{\mathrm{m}}\left(\mathrm{cm}^{3} \cdot \mathrm{mol}^{-1}\right)$ \\
{$\left[\mathrm{C}_{2} \mathrm{C}_{1} \mathrm{Im}\right]\left[\mathrm{C}_{1} \mathrm{CO}_{2}\right]^{40}$} & 105.3 & 1.0962 & 1.4950 & 155.27 & 45.62 \\
{$\left[\mathrm{C}_{2} \mathrm{C}_{1} \mathrm{Im}\right]\left[\mathrm{CF}_{3} \mathrm{SO}_{3}\right]^{30}$} & 35.72 & 1.3805 & 1.4315 & 189.06 & 48.85 \\
{$\left[\mathrm{C}_{2} \mathrm{C}_{1} \mathrm{Im}\right]\left[\mathrm{N}\left(\mathrm{CF}_{3} \mathrm{SO}_{2}\right)_{2}\right]^{41}$} & 27.10 & 1.5134 & 1.4216 & 258.56 & 65.65 \\
{$\left[\mathrm{C}_{2} \mathrm{C}_{1} \mathrm{Im}\right]\left[\mathrm{C}_{4} \mathrm{~F}_{9} \mathrm{CO}_{2}\right]^{30}$} & 83.32 & 1.4815 & 1.4405 & 252.56 & 60.68 \\
{$\left[\mathrm{C}_{2} \mathrm{C}_{1} \mathrm{Im}\right]\left[\mathrm{C}_{4} \mathrm{~F}_{9} \mathrm{SO}_{3}\right]^{30}$} & 124.7 & 1.5412 & 1.3969 & 266.16 & 64.09 \\
{$\left[\mathrm{C}_{2} \mathrm{C}_{1} \mathrm{py}\right]\left[\mathrm{C}_{4} \mathrm{~F}_{9} \mathrm{SO}_{3}\right]^{12}$} & 150.3 & 1.5098 & 1.4185 & 279.01 & 70.39 \\
\hline
\end{tabular}

Figure 3 shows that $\mathrm{R}-134 \mathrm{a}$ is the most soluble gas in all studied ILs, except in $\left[\mathrm{C}_{2} \mathrm{C}_{1} \mathrm{Im}\right]\left[\mathrm{C}_{1} \mathrm{CO}_{2}\right]$ which has better absorption capacity for R-125. The absorption of the three gases (specially of R125 and R-134a, which contain a higher number of fluorine atoms) is enhanced in FILs with respect to conventional ILs. These results highlight the key role of the fluorinated alkyl side chain (fluorinated nanosegregated domain) in the solubility of fluorinated gases. The gas solubility in the 
studied ILs is related to three types of phenomena: (i) a physical one, resulting from intermolecular interactions between solute and solvent (such as hydrogen bonding or electrostatic interactions, among others) which determine the enthalpic contribution to the physical absorption; (ii) a entropic one, that can also contribute to the gas solubility, and the free volume of the IL, that can create cavities where the gas molecules can accommodate; and (iii) a chemical one, meanly controlling the enthalpic contribution due to the formation of new intramolecular bonds between the F-gases and the IL.

The study of the cation nature for FILs containing the $\left[\mathrm{C}_{4} \mathrm{~F}_{9} \mathrm{SO}_{3}\right]^{-}$anion showed that the substitution of an imidazolium-based cation by a pyridinium-based cation does not change the gas absorption significatively (see Figure 3). Moreover, the study of the influence of the anion functional group shows that the solubility of the R-32 and R-134a is not affected by the substitution of a sulfonate group to a carboxylate group for imidazolium-based FILs. However, the presence of a carboxylate group slightly enhances the solubility of R-125 (see Figure 3). These results suggest a relevant role of the carboxylate group in the solubility of R-125 where a chemical solubility process may be significative. This fact may also explain the good solubility of this gas in $\left[\mathrm{C}_{2} \mathrm{C}_{1} \mathrm{Im}\right]\left[\mathrm{C}_{1} \mathrm{CO}_{2}\right]$.

Figure 4 compares the sorption isotherms determined in this work for $\left[\mathrm{C}_{2} \mathrm{C}_{1} \mathrm{Im}\right]\left[\mathrm{C}_{4} \mathrm{~F}_{9} \mathrm{SO}_{3}\right]$ and $\left[\mathrm{C}_{2} \mathrm{C}_{1} \mathrm{Im}\right]\left[\mathrm{N}\left(\mathrm{CF}_{3} \mathrm{SO}_{2}\right)_{2}\right]$ with those obtained with a conventional fluoro-containing IL, $\left[\mathrm{C}_{6} \mathrm{C}_{1} \mathrm{Im}\right]\left[\mathrm{N}\left(\mathrm{CF}_{3} \mathrm{SO}_{2}\right)_{2}\right]^{22,42}$. Taking these results into account, it is concluded that two main factors increase gas solubility at higher pressures in imidazolium-based ILs: the presence of a fluorinated domain (at least up to a four-carbon fluorinated alkyl chain) for R-134a and R-125; and the increment of the hydrogenated chain in the cation (at least up to a six-carbon chain) for F-gases. However, it has been widely reported in the literature that an increase in the hydrogenated or fluorinated alkyl chains is associated with increased toxicity. ${ }^{43}$ On the other hand, we have already demonstrated ${ }^{18}$ that FILs with up to four carbon atoms in the alkyl fluorinated chain have negligible 
toxicity. In this way, the presence of a fluorinated alkyl chain represents a less toxic approach to increase the solubility of fluorinated gases, specially R-134a and R-125. It is important to refer that our solubility data was obtained at $303.15 \mathrm{~K}$, the same temperature at which the solubility of R-32 and $\mathrm{R}-125$ in $\left[\mathrm{C}_{6} \mathrm{C}_{1} \mathrm{Im}\right]\left[\mathrm{N}\left(\mathrm{CF}_{3} \mathrm{SO}_{2}\right)_{2}\right]$ was reported. ${ }^{42}$ However, the solubility data for $\mathrm{R}-134 \mathrm{a}$ in $\left[\mathrm{C}_{6} \mathrm{C}_{1} \mathrm{Im}\right]\left[\mathrm{N}\left(\mathrm{CF}_{3} \mathrm{SO}_{2}\right)_{2}\right]$ was obtained at $298.15 \mathrm{~K}^{22}$
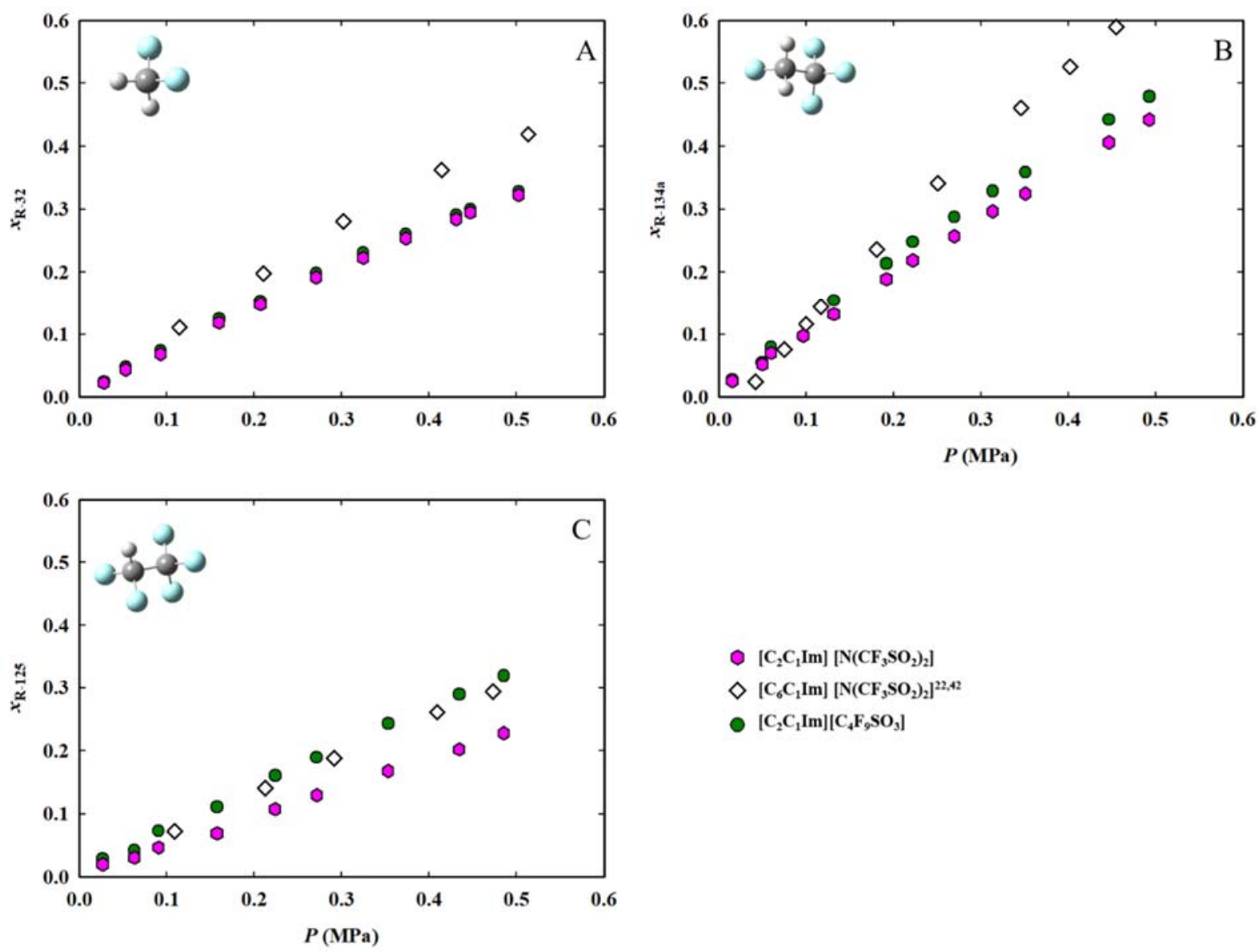

- $\left[\mathrm{C}_{2} \mathrm{C}_{1} \mathrm{Im}\right]\left[\mathrm{N}\left(\mathrm{CF}_{3} \mathrm{SO}_{2}\right)_{2}\right]$

$\diamond\left[\mathrm{C}_{6} \mathrm{C}_{1} \mathrm{Im}\right]\left[\mathrm{N}\left(\mathrm{CF}_{3} \mathrm{SO}_{2}\right)_{2}\right]^{22,42}$

- $\left[\mathrm{C}_{2} \mathrm{C}_{1} \mathrm{Im}\right]\left[\mathrm{C}_{4} \mathrm{~F}_{9} \mathrm{SO}_{3}\right]$

Figure 4. Sorption isotherms of R-32 (panel A), R-134a (panel B), and R-125 (panel C) refrigerants in ILs studied in this work and by other authors ${ }^{22,42}$ with different number of fluorine atoms in the anion and with different lengths of the hydrogenated chain in the cation. Isotherms were determined at $303.15 \mathrm{~K}$ (except for R-134a in $\left[\mathrm{C}_{6} \mathrm{C}_{1} \mathrm{Im}\right]\left[\mathrm{N}\left(\mathrm{CF}_{3} \mathrm{SO}_{2}\right)_{2}\right]$, which was determined at $298.15 \mathrm{~K}$ ) and equilibrium pressures ranging from 0.02 to $0.5 \mathrm{MPa}$. 
This paper also provides a critical review of the solubility data of the F-gases studied in this work in other ILs reported in the literature..$^{22,25,26,42,44-47}$ The nomenclature and abbreviations of the ILs reported in the literature are shown in Table S2 of Supporting Information. Figure 5 compares the experimental data determined in this work with those reported in the literature (see also Table S2 of Supporting Information) in terms of the Henry's constant, $H$, which for component $i$ is defined as:

$$
H_{i}(T, p)=\lim _{x_{i} \rightarrow 0} f_{i}^{\mathrm{L}} / x_{i}
$$

where $f_{i}^{\mathrm{L}}$ is the fugacity of the gas dissolved in the ionic liquid. Considering that under thermodynamic equilibrium the fugacity of the F-gas in the IL phase is equal to its fugacity in the gas phase, the fugacity is taken as the gas pressure and the Henry's law equation rewritten as:

$$
p_{i}=H_{i}(T) x_{i}
$$

where $p_{i}$ is the partial pressure of the F-gas. Strictly speaking, Henry's law relates the partial pressure of the F-gas to its solubility in IL phase under infinitely dilute conditions. The reported Henry's constants for the ILs studied in this work are the values extrapolated to zero pressure of second-order polynomial fittings of the experimental $(p, x)$ data. It is helpful to remember that a smaller value of the Henry's constant is related to a higher F-gas solubility. 


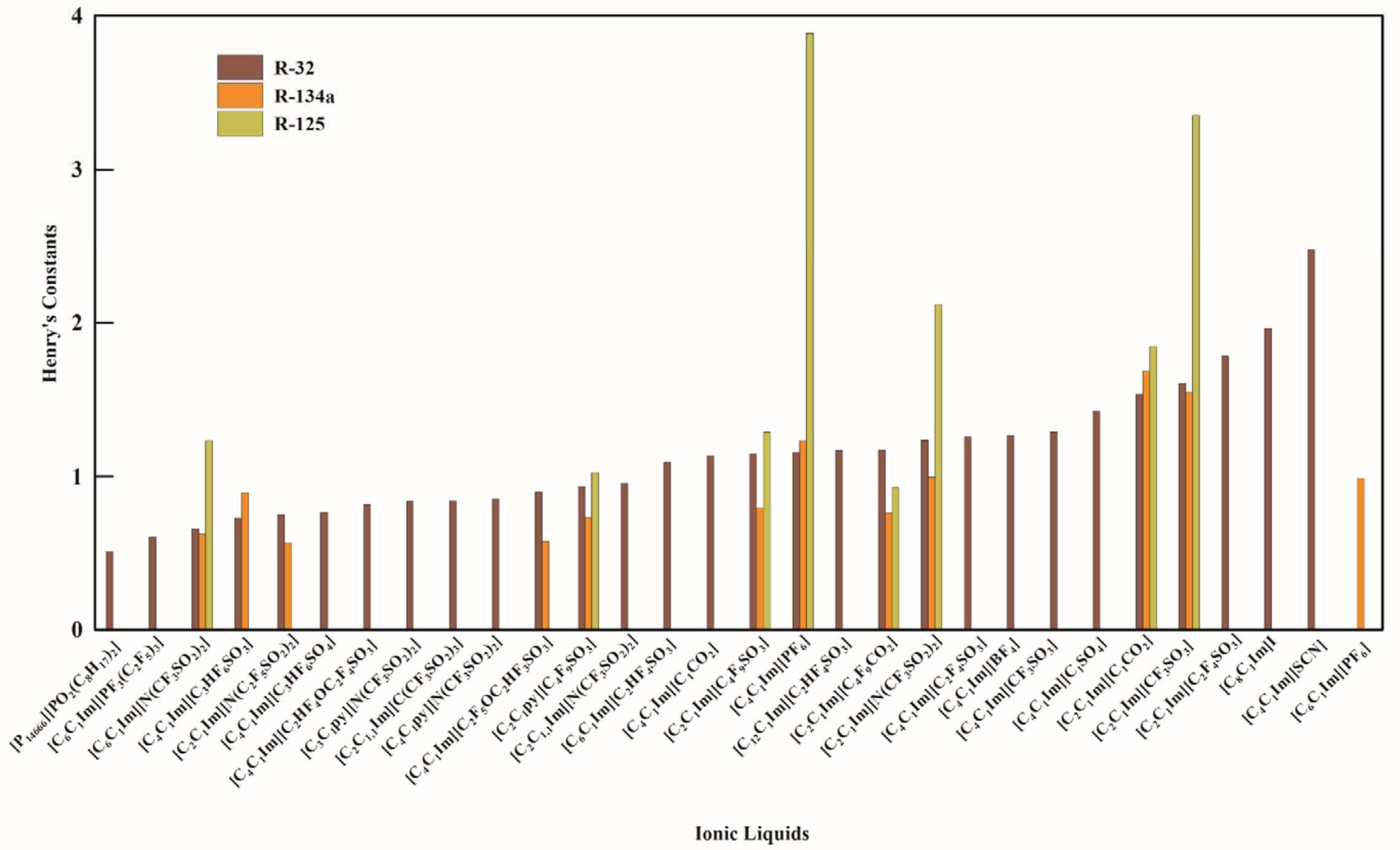

Figure 5. Henry's Law constants (in MPa) determined for the absorption of R-32, R-125, and R-134a in the ILs studied in this work and in others reported in the literature $22,25,26,42,44-47$, at $298.15 \mathrm{~K}$ or 303.15K (See Table S2 of Supporting Information). 
Of the three F-gases studied in this work, R-32 is the most studied in the literature using ILs as solvents. The best solubility for this F-gas is obtained with $\left[\mathrm{P}_{66614}\right]\left[\mathrm{PO}_{2}\left(\mathrm{C}_{8}\right)_{2}\right]$ IL, which has long hydrogenated alkyl chains. These chains can create cavities (higher free volume) where this F-gas can be accommodated. Conventional fluoro-containing imidazolium-based ILs with longer hydrogenated alkyl chains in the cation also present small Henry's constants for R-32, supporting the claim that the solubility of this gas is largely governed by entropic effects. In these imidazolium-based ILs, absorption is also improved with the increment of the number of carbon and fluorine atoms in the anion that also increases the molar volume and the free volume of these ILs (see Table 3). These results indicate that R-32 absorption is controlled by an entropic contribution where the free volume is of vital importance.

The ILs with the lowest Henry's constants for R-134a are the literature-reported $\left[\mathrm{C}_{2} \mathrm{C}_{1} \mathrm{Im}\right]\left[\mathrm{N}\left(\mathrm{C}_{2} \mathrm{~F}_{5} \mathrm{SO}_{2}\right)_{2}\right], \quad\left[\mathrm{C}_{4} \mathrm{C}_{1} \mathrm{Im}\right]\left[\mathrm{C}_{2} \mathrm{~F}_{5} \mathrm{OC}_{2} \mathrm{HF}_{3} \mathrm{SO}_{3}\right]$ and $\left[\mathrm{C}_{6} \mathrm{C}_{1} \mathrm{Im}\right]\left[\mathrm{N}\left(\mathrm{CF}_{3} \mathrm{SO}_{2}\right)_{2}\right] .{ }^{22,45}$ These Henry's constants are of the same order of magnitude as those for the three FILs studied in this work. A decrease in the Henry's constant is observed when the $\left[\mathrm{CF}_{3} \mathrm{SO}_{3}\right]^{-}$anion is substituted to $\left[\mathrm{N}\left(\mathrm{CF}_{3} \mathrm{SO}_{2}\right)_{2}\right]^{-}$or to $\left[\mathrm{N}\left(\mathrm{C}_{2} \mathrm{~F}_{5} \mathrm{SO}_{2}\right)_{2}\right]^{-}$in $\left[\mathrm{C}_{2} \mathrm{C}_{1} \mathrm{Im}\right]$-based ILs and when the $\left[\mathrm{C}_{2} \mathrm{C}_{1} \mathrm{Im}\right]^{+}$cation is substituted to $\left[\mathrm{C}_{6} \mathrm{C}_{1} I m\right]^{+}$in $\left[\mathrm{N}\left(\mathrm{CF}_{3} \mathrm{SO}_{2}\right)_{2}\right]$-based ILs. These two cases are related to an increment in the free volume of the IL and to an increase in the number of potential C-F- - - H-C or C-F- - F-C bonds between the IL and the F-gas. Moreover, we observed that the utilization of FILs, such as $\left[\mathrm{C}_{2} \mathrm{C}_{1} \mathrm{Im}\right]\left[\mathrm{C}_{4} \mathrm{~F}_{9} \mathrm{SO}_{3}\right]$ and $\left[\mathrm{C}_{2} \mathrm{C}_{1} \mathrm{Im}\right]\left[\mathrm{C}_{4} \mathrm{~F}_{9} \mathrm{CO}_{2}\right]$, improves gas sorption with respect to the corresponding fluoro-containing ILs $\left(\left[\mathrm{C}_{2} \mathrm{C}_{1} \mathrm{Im}\right]\left[\mathrm{CF}_{3} \mathrm{SO}_{3}\right]\right.$ and $\left.\left[\mathrm{C}_{2} \mathrm{C}_{1} \mathrm{Im}\right]\left[\mathrm{C}_{1} \mathrm{CO}_{2}\right]\right)$. This suggests that the absorption of R-134a is improved in ILs with higher free volumes and with the presence of the fluorinated nanosegregated domains. These nanosegregated domains contribute to an absorption controlled by physical effects, i.e. higher molar volume (see Table 3) and interactions $\mathrm{F}-\mathrm{-}-\mathrm{F}$ and $\mathrm{H}-\mathrm{-}-\mathrm{F}^{48-49}$ 
Solubility of R-125 in fluoro-containing ILs and FILs is lower than the one of R-134a. These two gases are very similar but in the case of R-125 one hydrogen atom is substituted by one fluorine atom. The decrease in the solubility of R-125 may be associated with the loss of one C-H (F-gas) - - - F-C (IL) interaction, or to a reduced flexibility of the gas molecule, which hampers its physical absorption. The lowest Henry's constants of R-125 were obtained for FILs and the highest values were obtained for fluoro-containing ILs. Therefore, in this case the utilization of FILs, which form three nanosegregated domains, improves gas absorption.

3.2 Correlation using NRTL model. The correct design of a separation process requires careful control and accurate knowledge of the thermodynamic properties and the phase behavior of the Fgases mixtures. The experimental data of this work were fitted by the NRTL (Non-Random TwoLiquid) model, which has been able to correlate satisfactorily the activity coefficients of different solutes in ILs. ${ }^{25,44,50,51}$

Consider the general condition for thermodynamic equilibrium between a pure F-gas, $i$, in the vapor phase and its absorption in an IL:

$$
f_{i}=\gamma_{i} x_{i} f_{i}^{\mathrm{o}}
$$

where $f_{i}$ is the F-gas's vapor-phase fugacity, which is well approximated by the pressure $p$ for the conditions of this study, $x_{i}$ and $\gamma_{i}$ are its mole fraction and activity coefficient in the IL phase, respectively, and $f_{i}^{\mathrm{o}}$ is its liquid-phase reference fugacity, which at the pressures under study is nearly the pure-component vapor pressure, $p_{i}^{*}$, at the same temperature as the mixture. In the NRTL model the activity coefficients for a binary mixture of F-gas (1) dissolved in an IL (2) phase are calculated as follows:

$$
\begin{aligned}
& \ln \gamma_{1}=x_{2}^{2}\left[\tau_{21}\left(\frac{G_{21}}{x_{1}+x_{2} G_{21}}\right)^{2}+\frac{\tau_{12} G_{12}}{\left(x_{2}+x_{1} G_{12}\right)^{2}}\right] \\
& \ln \gamma_{2}=x_{1}^{2}\left[\tau_{12}\left(\frac{G_{12}}{x_{2}+x_{1} G_{12}}\right)^{2}+\frac{\tau_{21} G_{21}}{\left(x_{1}+x_{2} G_{21}\right)^{2}}\right]
\end{aligned}
$$

where 
$G_{i j}=e^{-\alpha \tau_{i j}}$ and $\tau_{i j}=\frac{g_{i j}-g_{j j}}{R T}$

where $g_{i j}$ is the energy parameter between molecular surfaces $i$ and $j, R$ is the gas constant, and $T$ is the absolute temperature. The non-randomness parameter $\alpha$ was optimized and the dimensionless interaction parameters, $\tau_{12}$ and $\tau_{21}$, were used to correlate the experimental data for each binary mixture by least-squares minimization of the root mean standard deviation (RMSD) between the predicted and measured pressure values. The values of the non-randomness parameter $\alpha$ are listed in Table 4 together with the values of the NRTL binary parameters. The RMSD values given in Table 4 are lower than 0.03 for the binary F-gas+IL systems studied in this work. The solid lines in Figure 3 represent the mole fraction of F-gas for each F-gas+IL system calculated by the NRTL equation as a function of the applied F-gas pressure. The good agreement between experimental and calculated data shows that the NRTL model describes well the phase behavior of the studied mixtures. 


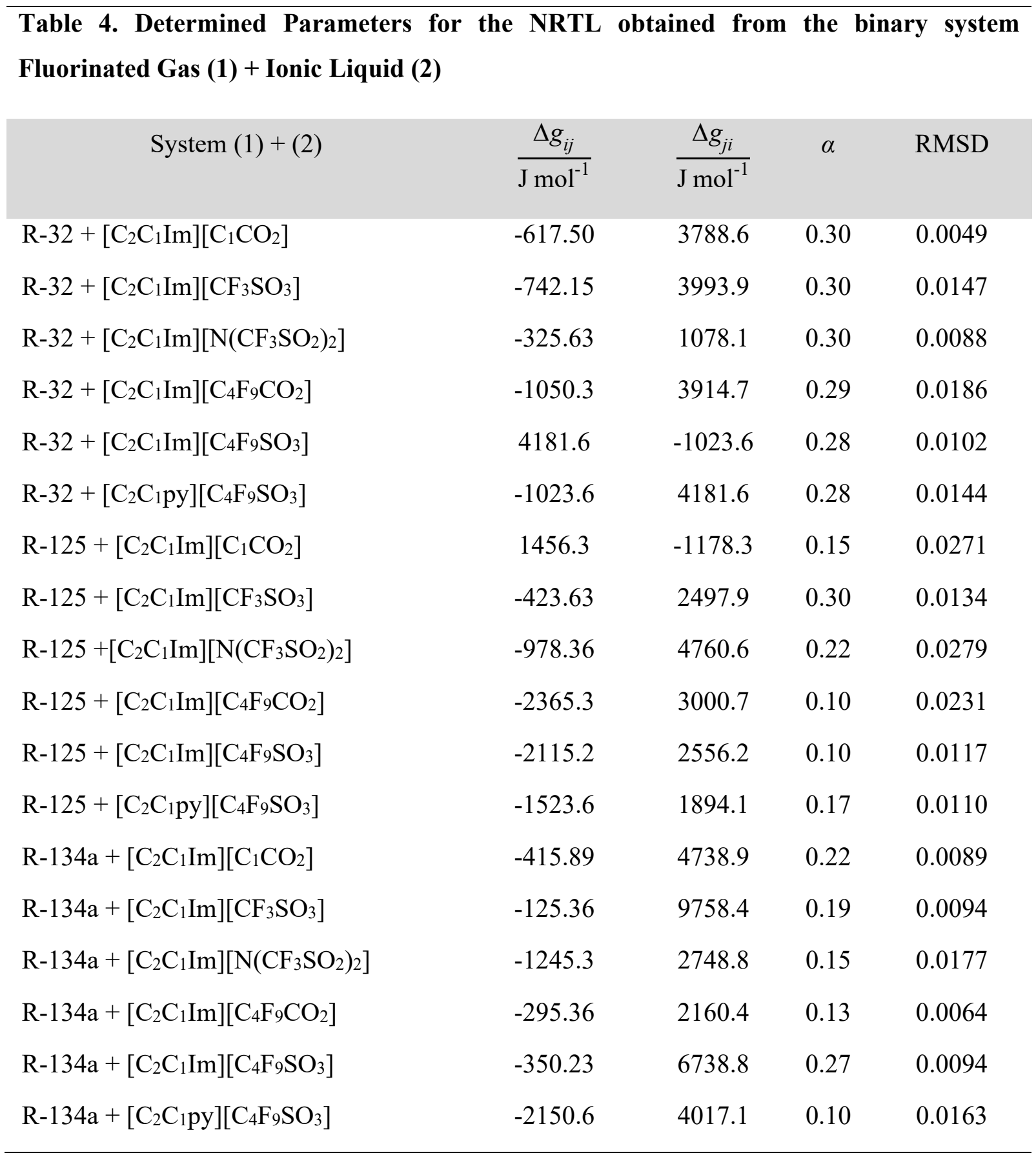


3.2 Ideal Selectivities. Different F-gases mixtures are used industrially and the selective separation of different pure F-gases from these gas mixtures is valuable. R-134a $+\mathrm{R}-32$ and R$134 \mathrm{a}+\mathrm{R}-125$ mixtures have not azeotrope and thus these mixtures can be separated through distillation. However, the most important constraint is related to the energy costs required in this separation process. The separation of $\mathrm{R}-32+\mathrm{R}-125$ mixture is not possible using distillation due to the existence of an azeotrope. Then, we investigated the separation of these F-gases mixtures through the selective absorption of pure F-gas in ILs. The ability of a pure IL to selectively absorb a gas from a mixture of gases is the most important characteristic in order to evaluate if a material or solvent is suitable for a specific gas separation process. We have determined the ideal selectivity for the binary mixtures of F-gases studied in this work in each pure IL over the full pressure range spanned experimentally. The ideal selectivity for a binary pair of gases $i$ and $j$ at a given pressure $P$ and temperature $T$ is expressed as the ratio of pure-gas solubilities in the IL:

$$
S_{i j}=\left(\frac{x_{i}}{x_{j}}\right)_{P, T}
$$

where $x_{i}$ and $x_{j}$ are the mole fraction of the dissolved gases $i$ and $j$, respectively, in the IL in equilibrium with its pure-vapor phase at pressure $P$ and temperature $T$.

The selectivities of the ILs studied in this work (see Table S3 of Supporting Information) have been compared with those of ILs available in the literature in Figure 6. $22,25,42,44,45$ The highest selectivities were obtained for the separation of R-134a $+\mathrm{R}-125$ and $\mathrm{R}-32+\mathrm{R}-125$, using the literature-reported $\mathrm{IL}\left[\mathrm{C}_{2} \mathrm{C}_{1} \mathrm{Im}\right]\left[\mathrm{PF}_{6}\right]$. However, it has been shown that $\mathrm{PF}_{6}$-based ILs decompose in aqueous media, at high temperatures or low $\mathrm{pH}$, originating corrosive fluoride compounds, such as $\mathrm{HF}^{52}$ This may restrict the utilization of $\left[\mathrm{C}_{2} \mathrm{C}_{1} \mathrm{Im}\right]\left[\mathrm{PF}_{6}\right]$ in separation processes, unless efficient processes, in which all water is removed from the system and where high temperatures are not used, are applied. Thus, the utilization of other ILs that do not present those problems may be a good alternative to avoid pre-treatment processes. 
The two fluoro-containing ILs studied in this work, $\left(\left[\mathrm{C}_{2} \mathrm{C}_{1} \operatorname{Im}\right]\left[\mathrm{CF}_{3} \mathrm{SO}_{3}\right]\right.$ and $\left.\left[\mathrm{C}_{2} \mathrm{C}_{1} \mathrm{Im}\right]\left[\mathrm{N}\left(\mathrm{CF}_{3} \mathrm{SO}_{2}\right)_{2}\right]\right)$, also present high selectivities for the separation of $\mathrm{R}-134 \mathrm{a}+\mathrm{R}-125$ and R-32 + R-125. In general, all FILs and conventional fluoro-containing ILs are selective for the separation of R-125 of the mixtures with R-134a and with R-32. However, the non-fluorinated IL, $\left[\mathrm{C}_{2} \mathrm{C}_{1} \mathrm{Im}\right]\left[\mathrm{C}_{1} \mathrm{CO}_{2}\right]$, shows low selectivity for the separations of these refrigerants. The lowest selectivities were obtained for the separation of R-134a + R-32, where FILs and two literaturereported ILs $\left(\left[\mathrm{C}_{4} \mathrm{C}_{1} \mathrm{Im}\right]\left[\mathrm{C}_{2} \mathrm{~F}_{5} \mathrm{OC}_{2} \mathrm{HF}_{3} \mathrm{SO}_{3}\right]\right.$ and $\left.\left[\mathrm{C}_{2} \mathrm{C}_{1} \mathrm{Im}\right]\left[\mathrm{N}\left(\mathrm{C}_{2} \mathrm{~F}_{5} \mathrm{SO}_{2}\right)_{2}\right]\right)$ present the best results. Thus, the increase in the number of fluorine atoms seems to favor the selectivity of ILs for the separation of R-134a + R-32 (the two refrigerants with the most different sizes). The opposite behavior is observed for the separation of R-134a + R-125, which have similar sizes, where fluorocontaining ILs yield the best results. On the other hand, the mixture R-32 + R-125 obtained the highest ideal selectivities with literature-reported IL $\left[\mathrm{C}_{4} \mathrm{C}_{1} \mathrm{Im}\right]\left[\mathrm{PF}_{6}\right]$ and for the two fluorocontaining ILs $\left(\left[\mathrm{C}_{2} \mathrm{C}_{1} \mathrm{Im}\right]\left[\mathrm{CF}_{3} \mathrm{SO}_{3}\right]\right.$ and $\left.\left[\mathrm{C}_{2} \mathrm{C}_{1} \mathrm{Im}\right]\left[\mathrm{N}\left(\mathrm{CF}_{3} \mathrm{SO}_{2}\right)_{2}\right]\right)$. For this separation, $\left[\mathrm{C}_{2} \mathrm{C}_{1} \mathrm{Im}\right]\left[\mathrm{C}_{4} \mathrm{~F}_{9} \mathrm{SO}_{3}\right]$ and $\left[\mathrm{C}_{2} \mathrm{C}_{1}\right.$ py $]\left[\mathrm{C}_{4} \mathrm{~F}_{9} \mathrm{SO}_{3}\right]$ presented selectivities close to 1 and $\left[\mathrm{C}_{2} \mathrm{C}_{1} \mathrm{Im}\right]\left[\mathrm{C}_{4} \mathrm{~F}_{9} \mathrm{CO}_{2}\right]$ was more selective towards $\mathrm{R}-125$ over $\mathrm{R}-32$.

The ideal selectivity can also be defined as the ratio of the Henry's law constants of the gases at a specific temperature:

$$
S_{i j}=\left(\frac{H_{i}}{H_{j}}\right)_{T}
$$

where $H_{i}$ and $H_{j}$ are the Henry's law constants for the gases $i$ and $j$, respectively. The results obtained with this equation, as expected, are similar to those obtained with Equation (13), with the same trends. 

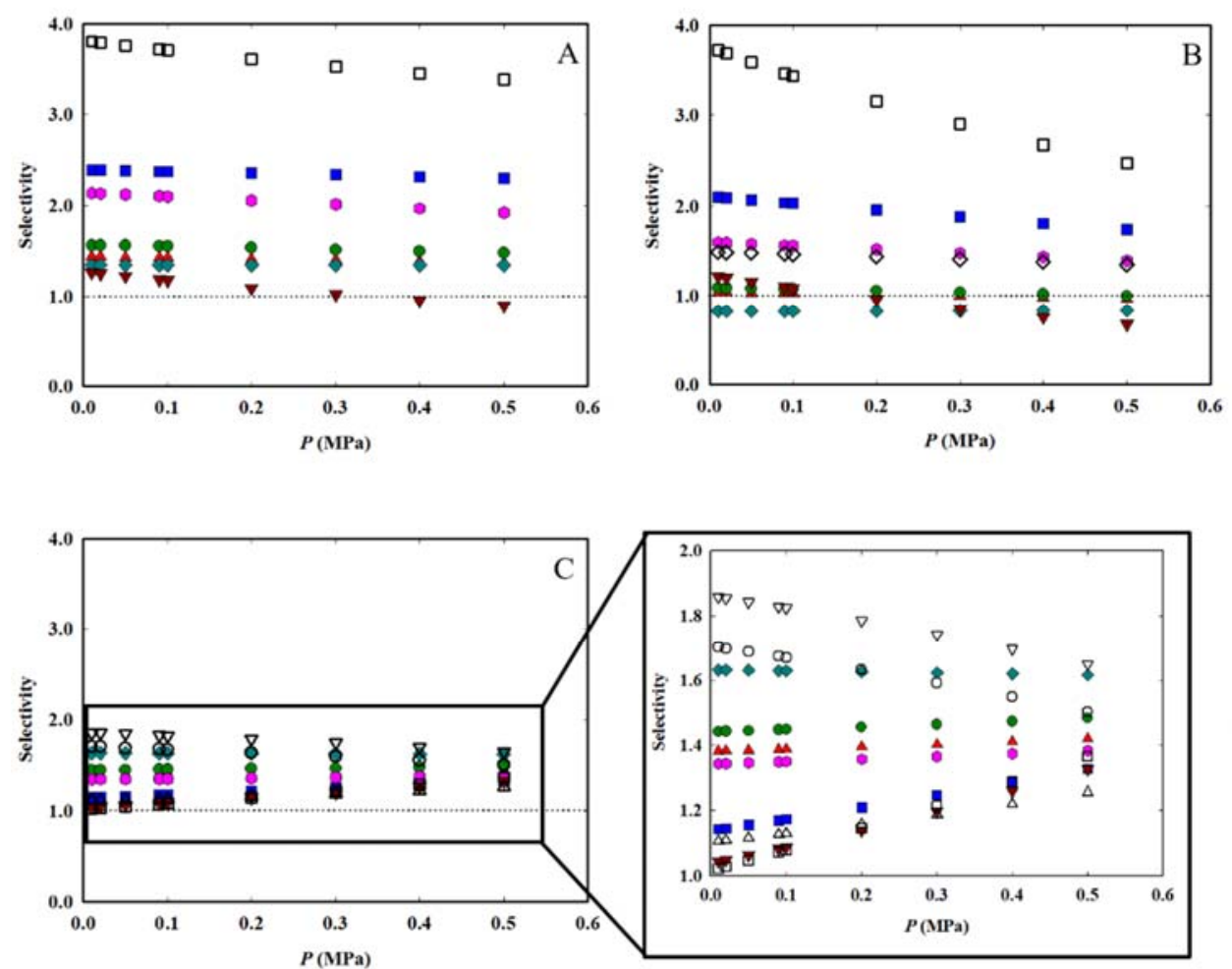

$\boldsymbol{\nabla}\left[\mathrm{C}_{2} \mathrm{C}_{1} \mathrm{Im}\right]\left[\mathrm{C}_{1} \mathrm{CO}_{2}\right]$

- $\left[\mathrm{C}_{2} \mathrm{C}_{1} \mathrm{Im}\right]\left[\mathrm{CF}, \mathrm{SO}_{3}\right]$

- $\left.\mid \mathrm{C}_{2} \mathrm{C}_{1} \mathrm{Im}\right]\left[\mathbf{N}\left(\mathrm{CF}_{3} \mathrm{SO}_{2}\right)_{2}\right]$

$\left.\diamond \mid \mathrm{C}_{2} \mathrm{C}_{1} \mathrm{Im}\right]\left|\mathrm{C}_{4} \mathrm{~F}_{3} \mathrm{CO}_{2}\right|$

- $\left.\left[\mathrm{C}_{2} \mathrm{C}_{1} \mathrm{Im}\right] \mid \mathrm{C}_{4} \mathrm{~F}_{3} \mathrm{SO}_{3}\right]$

$\Delta\left[\mathrm{C}_{2} \mathrm{C}_{1} \mathrm{Py}\right]\left[\mathrm{C}_{4} \mathrm{~F}_{9} \mathrm{SO}_{3}\right]$

○ $\left[\mathrm{C}_{2} \mathrm{C}_{1} \mathrm{Im}\right]\left[\mathrm{N}\left(\mathrm{C}_{2} \mathrm{~F}_{5} \mathrm{SO}_{2}\right)_{2}\right]^{2 s}$

口 $\left[\mathrm{C}_{4} \mathrm{C}_{1} \mathrm{Im}\right]\left[\mathrm{PF}_{6}\right]^{44}$

$\Delta\left[\mathrm{C}_{4} \mathrm{C}_{1} \mathrm{Im}\right]\left[\mathrm{C}_{3} \mathrm{HF}_{6} \mathrm{SO}_{3}\right]^{45}$

$\left.\nabla\left[\mathrm{C}_{4} \mathrm{C}_{1} \mathrm{Im}\right] \mid \mathrm{C}_{2} \mathrm{~F}_{3} \mathrm{OC}_{2} \mathrm{HF}_{3} \mathrm{SO}_{3}\right]^{2 \mathrm{~S}, \mathrm{~s}}$

$\diamond\left[\mathrm{C}_{6} \mathrm{C}_{1} \mathrm{Im}\right]\left[\mathrm{N}\left(\mathrm{CF}_{3} \mathrm{SO}_{2}\right)_{2}\right]^{2}$

Figure 6. Ideal selectivities of ILs studied in this work and ILs available in the literature $25,42,44,45$ for the separation of the refrigerants mixtures: R-134a + R-125 (panel A); R-32 + R-125 (panel B), and R-134a + R-32 (panel C where an ampliation of the selectivities range of 1 - 2 was incorporated for a better visualization) at $303.15 \mathrm{~K}$ and equilibrium pressures ranging from 0.01 to $0.5 \mathrm{MPa}$.

\section{CONCLUSIONS}

In the present work we studied the absorption of the three most used F-gases, R-32, R-125, and R-134, in various ILs with different cations and anions. The NRTL model was used to correlate the experimental data because the use of thermodynamic models allows the implementation of simulation studies for the design of extraction processes. The experimental results show that the absorption of these gases is considerably increased in ILs with alkyl fluorinated chains up to four carbons (FILs). Therefore, FILs may be an alternative to conventional ILs with longer hydrogenated chains, which are more toxic. The results obtained with the different ILs used in this work were compared with the ones available in the literature in order to evaluate the F-gas 
solubility capacity. This comparison was carried out using Henry's constants. The results demonstrated that the solubility of F-gases in ILs directly depends on the structure and the size of each F-gas.

Since those F-gases are utilized not only as pure gases, but also in gas mixtures, the utilization of ILs with selectivity towards specific F-gas is valuable. Ideal selectivity for the binary mixtures R-134a + R-125 and R-32 + R-125 was improved using fluoro-containing ILs, lacking an alkyl fluorinated chain. However, the selectivity for the mixture R-134a + R-32 was improved by utilizing FILs. This work delivers both fundamental understanding of the behavior of these new alternative solvents and the skills to manipulate their performance towards the design of separation processes of F-gases mixtures, such as R-410a (mixture of R-32 and R-125) and R-407f or R-407c (mixture of R32, R125 and R-134a). 


\section{AUTHOR INFORMATION}

\section{Corresponding Author}

*E-mail: jmmda@fct.unl.pt (J.M.M. Araújo) and anab@fct.unl.pt (A.B. Pereiro), Fax: (+351) 212948550; Tel: (+351) 212948318.

\section{ACKNOWLEDGMENTS}

The authors would like to acknowledge the funding of the KET4F-Gas project, SOE2/P1/P0823, co-funded by the Interreg Sudoe Programme through the European Regional Development Fund (ERDF). A.B. Pereiro and J.M.M. Araújo acknowledge FCT/MCTES for financial support through IF/00190/2014 contract and IF/00210/2014 contract, respectively. Rui Ribeiro acknowledges financial support through the Norma Transitória DL 57/2016 Program Contract (FCT/MCTES). This work was also supported by the Associate Laboratory for Green Chemistry - LAQV, which is financed by national funds from FCT/MCTES (UID/QUI/50006/2019).

SUPPORTING INFORMATION: The Supporting Information is available free of charge on the ACS Publications website. Supplementary figure representing comparison of data of $\mathrm{CO}_{2}$ absorption; tables containing molar absorption fraction of refrigerants R-32, R-125, and R-134a in the ILs studied in this work, Henry's law constant, and the ideal selectivities of ILs studied in this work for the separation of the refrigerants mixtures R-134a + R-125, R-32 + R-125, and R-134a+ $\mathrm{R}-32$. 


\section{REFERENCES}

(1) United States Environmental Protection Agency: Overview of Greenhouse Gases. https://www.epa.gov/ghgemissions/overview-greenhouse-gases (accessed July 31, 2019).

(2) United States Environmental Protection Agency: Global Greenhouse Gas Emissions Data. https://www.epa.gov/ghgemissions/global-greenhouse-gas-emissions-data (accessed July 31, 2019).

(3) European Environment Agency: EEA greenhouse gas - data viewer. https://www.eea.europa.eu/data-and-maps/data/data-viewers/greenhouse-gases-viewer (accessed July 31,2019$)$.

(4) European Environment Agency. National emissions reported to the UNFCCC and to the EU Greenhouse Gas Monitoring Mechanism. Data Greenh Gas Emiss Removals, Sent by Ctries to UNFCCC EU Greenh Gas Monit Mech (EU Memb States) 2018.

(5) European Union. Regulation (EU) No 517/2014 of the European Parliament and of the Council of 16 April 2014 on fluorinated greenhouse gases and repealing Regulation (EC) No $842 / 20062014$.

(6) Heath, E. Amendment to the Montreal Protocol on Substances that Deplete the Ozone Layer (Kigali Amendment). International Legal Materials 2017, 56(1), 193-205.

(7) ONU Medio Ambiente : The Kigali Amendment to the Montreal Protocol- Another Global Commitment to stop climate change. https://www.unenvironment.org/es/node/20806 (accessed July 31,2019$)$.

(8) European Commission: Fluorinated greenhouse gases https://ec.europa.eu/clima/policies/f-gas_en (accessed July 31, 2019). 
(9) Tsai, W.; Chen, H.; Hsien, W. A review of uses, environmental hazards and recovery/recycle technologies of perfluorocarbons (PFCs) emissions from the semiconductor manufacturing processes. Journal of Loss Prevention in the Process Industries 2002, 15(2), 6575.

(10) Regel-Rosocka, M.; Materna, K. Ionic Liquids for Separation of Metal Ions and Organic Compounds from Aqueous Solutions. Ionic Liquids in Separation Technology 2014, 153-188.

(11) Bélafi-Bakó, K.; Nemestóthy, N.; Bakonyi, P. Separation of Gases Using Membranes Containing Ionic Liquids. Ionic Liquids in Separation Technology 2014, 261-273.

(12) Pereiro, A.B.; Araújo, J.M.M.; Martinho, S.; Alves F.; Nunes, S.; Matias, A.; Duarte, C.M.M.; Rebelo, L.P.N.; Marrucho, I.M. Fluorinated Ionic Liquids: Properties and Applications. ACS Sustainable Chem. Eng. 2013, 1(4), 427-439.

(13) Pereiro, A.B.; Pastoriza-Gallego, M.J.; Shimizu, K.; Marrucho, I.M.; Lopes, J.N.C.; Piñeiro, M.M. On the Formation of a Third, Nanostructured Domain in Ionic Liquids. $J$ Phys Chem B. 2013, 117(37), 10826-10833.

(14) Ferreira, M.L; Pastoriza-Gallego, M.J.; Araújo, J.M.M.; Lopes, J.N.C; Rebelo, L.P.N.; Piñeiro, M.M.; Shimizull, K.; Pereiro, A.B. Influence of Nanosegregation on the Phase Behavior of Fluorinated Ionic Liquids. J. Phys. Chem. 2017, 121(9), 5415-5427.

(15) Pereiro, A.B.; Tomé, L.C.; Martinho, S.; Rebelo, L.P.N.; Marrucho, I.M. Gas Permeation Properties of Fluorinated Ionic Liquids. Ind. Eng. Chem. Res. 2013, 52(14), 4994-5001.

(16) Pereiro, A.B.; Araújo, J.M.M.; Martinho, S.; Alves F.; Nunes, S.; Matias, A.; Duarte, C.M.M.; Rebelo, L.P.N.; Marrucho, I.M. Fluorinated Ionic Liquids: Properties and Applications. ACS Sustainable Chem. Eng. 2013, 1(4), 427-439. 
(17) Vieira, N.S.M.; Bastos, J.C.; Rebelo, L.P.N.; Matias, A.; Araújo, J.M.M.; Pereiro, A.B. Human cytotoxicity and octanol/water partition coefficients of fluorinated ionic liquids. Chemosphere 2019, 216, 576-586.

(18) Vieira, N.S.M.; Stolte, S.; Araújo, J.M.; Rebelo, L.P.N.; Pereiro, A.B.; Markiewicz, M. Acute Aquatic Toxicity and Biodegradability of Fluorinated Ionic Liquids. ACS Sustainable Chem. Eng 2019, 7(4), 3733-3741.

(19) Pereiro, A.B.; Araújo, J.M.M.; Teixeira, F.S.; Marrucho, I.M.; Piñeiro, M.M.; Rebelo, L.P.N. Aggregation Behavior and Total Miscibility of Fluorinated Ionic Liquids in Water. Langmuir 2015, 3(14), 1283-1295

(20) Shiflett, M.B.; Yokozeki, A. Phase Behavior of Carbon Dioxide in Ionic Liquids: $[\mathrm{emim}][$ Acetate $],[\mathrm{emim}][$ Trifluoroacetate $]$, and $[\mathrm{emim}][$ Acetate $]+[\mathrm{emim}][$ Trifluoroacetate $]$ Mixtures. Chem. Eng. Data 2009, 54(1), 108-114.

(21) Shiflett, M.B; Yokozeki, A. Solubility Differences of Halocarbon Isomers in Ionic Liquid [emim][Tf 2 N]. J. Chem. Eng. Data 2007, 52(5), 2007-2015.

(22) Ren, W.; Scurto, A.M. Phase equilibria of imidazolium ionic liquids and the refrigerant gas, 1,1,1,2-tetrafluoroethane (R-134a). Fluid Phase Equilibria 2009, 286(1), 1-7.

(23) Shiflett, M.B; Yokozeki, A. Binary Vapor-Liquid and Vapor-Liquid-Liquid Equilibria of Hydrofluorocarbons (HFC-125 and HFC-143a) and Hydrofluoroethers (HFE-125 and HFE-143a) with Ionic Liquid [emim][Tf2N]. J. Phys. Chem 2008, 53(2), 492-497.

(24) Liu, X.; He, M.; Ly, N.; Qi, X.; Su, C. Solubilities of R-161 and R-143a in 1-Hexyl-3methylimidazolium bis(trifluoromethylsulfonyl)imide. Fluid Phase Equilibria 2015, 388, 37-42. (25) Shiflett, M.B.; Harmer, A.; Junk, C.P.; Yokoxeki, A. Solubility and Diffusivity of Difluoromethane in Room-Temperature Ionic Liquids. Chem. Eng. Data 2006, 51(2), 483-495. 
(26) Dong, L.; Zheng, D.; Sun, G.; Wu, X. Vapor-Liquid Equilibrium Measurements of Difluoromethane $+[$ Emim $]$ OTf, Difluoromethane $+[$ Bmim $]$ OTf, Difluoroethane $+[$ Emim $]$ OTf, and Difluoroethane $+[$ Bmim]OTf Systems. Journal of Chemical \& Engineering Data 2011, 56(9), 3663-3668.

(27) Öko-Recherche: Briefing Paper: Availability of alternatives to HFCs in commercial refrigeration in the EU. https://www.oekorecherche.de/en/node/205 (accessed July 31, 2019).

(28) Hu, Y.; Azevedo, E.G.; Prausnitz, J.M. The molecular basis for local compositions in liquid mixture models.Fluid Phase Equilibria 1983, (13), 351-360.

(29) Reid R. C., Prausnitz J. M., Poling B. E., The Properties of Gases \& Liquids, $4^{\text {th }}$ Edition, McGraw-Hill, 1988.

(30) Vieira, N. S. M.; Reis, P. M.; Shimizu, K.; Cortes, O. A.; Marrucho, I. M.; Araujo, J. M. M.; Esperanca, J. M. S. S.; Lopes, J. N. C.; Pereiro, A. B.; Rebelo, L. P. N. A thermophysical and structural characterization of ionic liquids with alkyl and perfluoroalkyl side chains. $R S C A d v$. 2015, 5(80), 65337-65350.

(31) Vieira, N. S. M.; Luís, A.; Reis, P. M.; Carvalho, P. J.; Lopes-da-Silva, J. A.; Esperança, J. M. S. S.; Araújo, J. M. M.; Rebelo, L. P. N.; Freire, M. G.; Pereiro, A. B. Fluorination effects on the thermodynamic, thermophysical and surface properties of ionic liquids. J. Chem. Thermodyn. 2016, 97, 354-361.

(32) Ribeiro, R.P.P.L.; Antunes, C.L.; Garate, AU, Portela, AF, Plaza, MG, Mota, JPB, et al. Binderless shaped metal-organic framework particles: Impact on carbon dioxide adsorption. Microporous Mesoporous Mater 2019, 275, 111-121. 
(33) Camacho, B.C.R.; Ribeiro, R.P.P.L.; Esteves, I.A.A.C; Mota, J.P.B. Adsorption equilibrium of carbon dioxide and nitrogen on the MIL-53(Al) metal organic framework. Sep Purif Technol 2015, 141 (12), 150-159.

(34) Nabais, A.R.; Ribeiro, R.P.P.L.; Mota, J.P.B.; Alves, V.D.; Esteves, I.A.A.C.; Neves, L.A. $\mathrm{CO} 2 / \mathrm{N} 2$ gas separation using Fe(BTC)-based mixed matrix membranes: A view on the adsorptive and filler properties of metal-organic frameworks. Sep Purif Technol 2018, 202(31), 174-184.

(35) Shiflett, M.B.; Shiflett, A.D.; Yokozeki, A. Separation of tetrafluoroethylene and carbon dioxide using ionic liquids. Separation and Purification Technology 2011, 79(3), 357- 364.

(36) Sousa, J. M. M. V.; Queimada, A. J. B.; Macedo, E. A.; Fonseca, I.M.A. Solubility of hydrofluorocarbons in aromatic solvents and alcohols: Experimental data and modeling with CPA EoS. Fluid Phase Equilibria 2013, 337(15), 60-66.

(37) Sousa, J. M. M. V. ; Almeida, J. P. B.; Ferreira, A. G. M.; Fachada, H. C.; Fonseca, I.M.A. Solubility of HFCs in lower alcohols. Fluid Phase Equilibria 2011, 303(2), 115-119.

(38) Tseregounis, S. I.; Riley, M. J. Solubility of HFC-134a Refrigerant in Glycol-Type Compounds: Effects of Glycol Structure. Environmental and Energy Engineering 1994, 40(4), 726-737.

(39) Chaudhari, S. K.; Salavera, D.; Esteve, X.; Coronas, A. Vapour-liquid equilibria of the system 1,1,1,2-tetrafluoroethane+monoethylene-glycol dimethylether from 283.15 to $353.15 \mathrm{~K}$ : New modified UNIFAC parameters. Fluid Phase Equilibria 2008, 271 (1-2), 28-33.

(40) Freire, M.G.; Teles, A. R. R.; Rocha, M. A. A.; Schroder, B.; Neves, C. M. S. S.; Carvalho, P. J.; Evtuguin, D.V.; Santos, L. M. N. B. F.; Coutinho, J. A. P. Thermophysical Characterization of Ionic Liquids Able To Dissolve Biomass. Journal of Chemical and Engineering Data 2011, 56 (12), 4813-4822. 
(41) Froba, A. P.; Kremer. Heiko.; Leipertz, A.; Density, Refractive Index, Interfacial Tension, and Viscosity of Ionic Liquids [EMIM][EtSO 4$],[E M I M]\left[\mathrm{NTf}_{2}\right],[\mathrm{EMIM}]\left[\mathrm{N}(\mathrm{CN})_{2}\right]$, and $[\mathrm{OMA}]\left[\mathrm{NTf}_{2}\right]$ in Dependence onTemperature at Atmospheric Pressure. Journal of Physical Chemistry B 2008, 112 (39), 12420-12430.

(42) Liu, X.; He, M.; Lv, N.; Qi, X.; Su, C. Vapor-Liquid Equilibrium of Three Hydrofluorocarbons with [HMIM][Tf2N]. Chem. Eng. Data 2015, 60(5), 1354-1361.

(43) Egorova, K. S.; Ananikov, V. P. Toxicity of ionic liquids: eco (cyto) activity as complicated, but unavoidable parameter for task-specific optimization. Chem. Sus. Chem. 2014, 7, 336-360.

(44) Shiflett, M. B.; Yokozeki, A. Solubility and Diffusivity of Hydrofluorocarbons in RoomTemperature Ionic Liquids. AIChE Journal 2006, 52(3), 1205-1219.

(45) Shiflett, M. B.; Yokozeki, A. Absorption cycle utilizing ionic liquid as working Uid, EP1846535A1. Febrary 4, 2005.

(46) Liu, X.; Pan, P.; He, M. Vapor-liquid equilibrium and diffusion coefficients of R32 + [HMIM][FEP], R152a + [HMIM][FEP] and R161 + [HMIM][FEP]. Journal of Molecular Liquids 2018, 253, 28-35.

(47) Liu, Xiangyang.; Lv, Nan.; Su, Chao.; He. Maogang.; Solubilities of R32, R245fa, R227ea and R236fa in a Phosphonium-Based Ionic Liquid. Journal of Molecular Liquids 2016, $2018,525-530$.

(48) Cavallo, G.; Metrangolo, P.; Milani, R.; Pilati, T.; Priimagi, A.; Resnati, G.; Terraneo, G. The Halogen Bond 2016, 116(4), 2478-2601. 
(49) Panini, P.; Chopra, D. Understanding of Non-covalent Interactions Involving Organic Fluorine. In Hydrogen Bonded Supramolecular Structures; Lecture Notes in Chemistry; SpringerVerlag: Berlin, Heidelberg 2015, 87,37 - 67.

(50) Zoubeik, M.; Mohamedali, M.; Henni, A. Experimental solubility and thermodynamic modeling of $\mathrm{CO} 2$ in four new imidazolium and pyridinium-based ionic liquids. Fluid Phase Equilibria 2016, 419, 67-74

(51) Rocha, M.; Shiflett, M. B. Water Sorption and Diffusivity in [C2C1im][BF4], $[\mathrm{C} 4 \mathrm{C} 1 \mathrm{im}][\mathrm{OAc}]$, and $[\mathrm{C} 4 \mathrm{C} 1 \mathrm{im}][\mathrm{Cl}]$. Industrial \& Engineering Chemistry Research 2019, 58(4), 1743-1753.

(52) Freire, M.G.; Neves, C.M.S.S.; Marrucho, I.M.; Coutinho J.A.P.; Fernandes, A. M. Hydrolysis of Tetrafluoroborate and Hexafluorophosphate Counter Ions in Imidazolium-Based Ionic Liquids. J. Phys. Chem. A 2010, 114, 3744-3749. 


\section{Table of Contents Graphic}

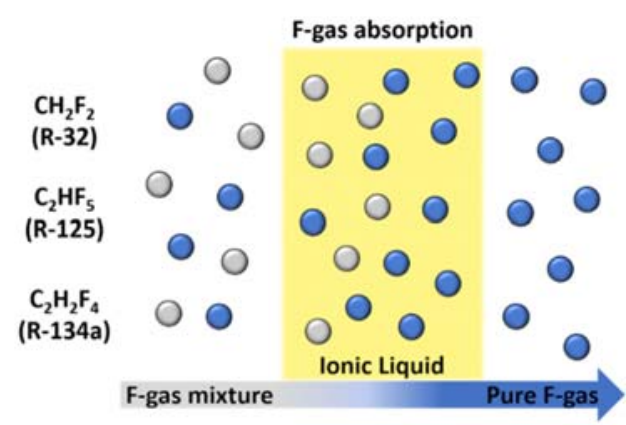

